\title{
The Application of Salutogenesis in Vocational Rehabilitation Settings
}

\author{
Monica Lillefjell, Ruca Maass, and Camilla Ihlebæk
}

\section{Introduction}

Vocational rehabilitation is a combination of medical, psychological, social, and occupational activities aiming to re-establish, among sick or injured people with previous work history, their work capacity and prerequisites for returning to work (Ahlgren, Bergroth, Ekholm, \& Schüldt, 2007). This chapter aims at providing a salutogenic orientation to vocational rehabilitation, and we explore how a salutogenic perspective applied in practical rehabilitation can be beneficial in rehabilitation settingVocational rehabilitations including specialist health services, private rehabilitation institutions, Green Care- Agriculture welfare services, and workplace rehabilitation for employees on sick leave.

Antonovsky (1979) stated that his writings on salutogenesis were aimed at all those who are "committed to understanding and enhancing the adaptive capabilities of human beings," clearly inclusive of the field of rehabilitation. Individuals who are in a rehabilitation process face constant challenges, and the outcome of the rehabilitation, at biological, psychological, and social levels, depends on their capability to deal with, overcome, and recover from these challenges. According to Antonovsky's theory, this capability depends on the strength of the individual's sense of coherence, determined by an individual's general resistant resources.

M. Lillefjell $(\bowtie) \bullet$ R. Maass

Department of Health Science, Faculty of Health and Social Science, Center for Health Promotion Research, Norwegian University of

Science and Technology (NTNU), Trondheim, Norway

e-mail: monica.lillefjell@ntnu.no; Ruca.e.maass@ntnu.no

C. Ihlebæk

Section of Public Health, ILP, Norwegian University of Life Sciences, Ås, Norway

Østfold University College, Moss, Norway

e-mail: Camilla.ihlebak@nmbu.no
There is evidence that rehabilitation is facilitated by the adoption and practical application of a salutogenic approach (Griffiths, 2009). The WHO definition of rehabilitation states:

Rehabilitation of people with disabilities is a process aimed at enabling them to reach and maintain their optimal physical, sensory, intellectual, psychological, and social functional levels. Rehabilitation provides disabled people with the tools they need to attain independence and self-determination (WHO, 2011).

In line with this definition, Antonovsky (1991) defined recovery as a constructive process in which the individual focuses on their own situation in a flexible, adaptive, and future-oriented way. He argued that for adults, the work environment is the most important setting in determining an individual's sense of coherence. Vocation can strengthen the sense of coherence when expectations are known and consistent, when a worker experiences having the resources required to complete job tasks, and when the worker believes that he/she has a shared responsibility (Lustig, Rosenthal, Strauser, \& Haynes, 2000). Sense of coherence is a factor in work-related phenomena such as sick leave processes (Falkdal, Edlund, \& Dahlgren, 2006), disability leading to pension (Suominen et al., 2005), work and well-being (Virtanen \& Koivisto, 2001), work attitudes (Axelsson, Andersson, Håkansson, \& Ejlertsson, 2005), work stressors and strain (Höge \& Büssing, 2004; Kivimäki, Kalimo, \& Toppinen, 1998), profession or kind of employment (Lundberg \& Nyström Peck, 1994), and quality of work (Volanen, Lahelma, Silventoinen, \& Suominen, 2004).

According to Ilmarinen (2006), return to work or work ability is built on the balance between a person's resources and work demands. Besides the work environment, individual factors that affect work ability include functional capacity, competence (knowledge and skills), and values and motivation. Non-work factors known to influence work ability include family, friends, and relatives and the broader social and policy environment (Ilmarinen, 2006). 


\section{Descriptive Research}

Return to work after a period with disability leave has often been studied in terms of clinical factors, objective measures of trauma, pain, and musculoskeletal diseases (Shaw, Segal, Poljatako, \& Harburn, 2002), or how social expectations and values influence attitudes towards employment (Jakobsen, 2004). Coordinated and tailored multidisciplinary rehabilitation programs that include psychosocial pain management and physical exercise intervention, are more effective in improving function and return to work than programs that do not include psychosocial interventions (Guzman et al., 2002; Hoffman, Papas, Chatkoff, \& Kerns, 2007; Staal, Rainville, Fritz, van Mechelen, \& Pransky, 2005).

Hoefsmit, Houkes, and Nijhuis (2012) identified characteristics of return to work (RTW) interventions that facilitated RTW in multiple populations and across interventions, and concluded that multidisciplinary interventions were effective. This conclusion is supported by Franche et al. (2005) for workplace-based RTW interventions aimed to reduce work disability duration and associated costs.

In the last decade, an increasing number of persons with mental, physical, and social problems have participated in Green Care services in the Nordic countries and other European countries (Batt-Rawden \& Tellnes, 2009). Green Care is the use of farms as an arena for health promotion, rehabilitation, and social interventions to improve the coping abilities, participation, empowerment, and quality of life of rehabilitation clients (Batt-Rawden \& Tellnes, 2009; Hassink, Elings, Zweekhorst, van den Nieuwenhuizen, \& Smit, 2010).

Sense of coherence is a predictor of the outcome of vocational rehabilitation (Kaiser, Mattsson, Marklund, \& Wimo, 2006). Several studies underline that rehabilitation services should ensure that they have rehabilitation goals that strengthen individuals' sense of coherence (Engström \& Janson, 2009; Griffiths, 2009; Kaiser, Mattsson, Marklund, \& Wimo, 2001; Kaiser et al., 2006; Lillefjell, 2008; Newton, 1999). Engström and Janson (2009) found that a high level of sense of coherence counteracts short as well as long-term sickness absence. As an example of dramatic recovery, liver transplant recipients with higher levels of hardiness and higher sense of coherence scores demonstrated higher RTW rates compared to those with lower scores (Newton, 1999). In accordance are findings of Ramel, Rosberg, Dahlin, and Cederlund (2003), who found that the RTW process after serious hand injury was more dependent on the person's own ability and motivation, including sense of coherence, than on the severity of the injury. Additionally, both personal resources (a strong sense of coherence) and the presence of a sufficient social network have been observed to buffer the negative influence of disabilities on life satisfaction (Anke \& FuglMeyer, 2004).

Bildt, Backstig, and Andersson Hjelm (2006) examined the associations between physical and psychological stress factors in and outside work, sickness absence, and cardiovascular and musculoskeletal diseases. The impact on sickness absence consisted mainly of demand and control aspects of the psychosocial working conditions, but also on employment security, and level of the sense of coherence; low sense of coherence was found to exacerbate musculoskeletal complaints. In accordance are results from a 10-year follow-up study comparing psychosocial factors in healthy persons and sick-listed persons with musculoskeletal disorders (MSD); there was significantly higher quality of life, more control over the working situation, and a better sense of coherence in the healthy group compared to the MSD group (Lydell, Marklund, Baigi, Mattsson, \& Måånsson, 2011).

Evaluation of workplace-based early rehabilitation in Finland showed that during the rehabilitation period, the performance of participants began to match that of an at-work comparison group, especially with respect to work capacity, mental well-being, and musculoskeletal problems (Väänänen-Tomppo, Janatuinen, \& Törnqvist, 2005). Sense of coherence actually rose in both groups, attributed in part to positive changes in the workplace. In contrast, a study of employee and work-related predictors for entering rehabilitation observed that sense of coherence was not associated with return to work (Lamminpää, Kuoppala, VäänänenTomppo, \& Hinkka, 2012).

Volanen et al. (2010) found the sense of coherence to be associated with intentions to retire early among women and men reporting somatic or mental illness; this association was not influenced by socioeconomic, psychosocial, and work and health behavior. Kaiser et al. (2006) found that 3 years after the vocational rehabilitation process had ended, men who received disability pension had significantly lower sense of coherence scores than those who did not receive disability pension, and women who received disability pension had stronger sense of coherence than men who received disability pension. The gender difference might be related to a societal belief in women's greater vulnerability to musculoskeletal disorder. The income disparity between men and women, with lower income for women, is probably also of importance. Thus, the findings of descriptive research indicate that the level of the sense of coherence is a factor in rehabilitation processes (Lillefjell, 2006). 


\section{Intervention Research}

A vast amount of interventions exist that aim to facilitate RTW after sickness absence. These interventions are usually focused on specific target populations such as employees with low back pain, stress-related complaints, or adjustment disorders. The majority of RTW interventions for sickness absence beneficiaries involve some form of cognitivebehavioral treatment to improve cognitive skills in relation to work (Franche et al., 2005; Martin et al., 2013). Some interventions showing promising results also include contact with the workplace or aim at restoring contact with the workplace (Martin et al., 2013).

Salutogenic theory is found to help explain the process of recovery for those with mental health issues (Griffiths, 2009); there is substantial evidence that sense of coherence plays a central role in coping with stressors in the rehabilitation process, and that it contributes to mental health and psychosocial functioning. Moreover, sense of coherence is found to increase through work rehabilitation programs and re-employment (Lillefjell \& Jakobsen, 2007; Vastamaki, Moser, \& Paul, 2009). For example, a Finnish unemployed sample significantly improved the sense of coherence through intervention, and re-employed individuals experienced the greatest improvements (Vastamaki et al., 2009). This included changes in comprehensibility, manageability, and meaningfulness.

Hansen, Edlund, and Bränholm (2005) identified predictors of individual resources for a return to work among persons on sick leave. There were significant differences between the study group and the reference groups in sense of coherence, locus of control, life satisfaction, and coping resources. The most important predictive factors were previous sick leave, own belief about future, and self-reported symptoms. A study among unskilled Danish public employees and privately employed housecleaners on sick leave due to musculoskeletal and/or common mental illnesses found support for the salutogenic theory (Jensen Claudi, 2013); work ability expressed as the intention to work was decisive for RTW, reflecting the interpretation of the work/health situation as comprehensible, meaningful, and manageable.

A study by Lillefjell and Jakobsen (2007) investigated the association between the sense of coherence and work re-entry following vocational rehabilitation among patients with musculoskeletal pain. Sense of coherence significantly improved, and pain experience, anxiety, and depression significantly decreased during the rehabilitation period. Sense of coherence was found to significantly predict anxiety and depression in a non-RTW subsample. However no significant association was found between the sense of coherence and RTW. These data clarify the role of the sense of coherence in coping with chronic pain and emotional distress, but question the presumed role of the sense of coherence in work re-entry of persons with long-term chronic musculoskeletal pain. In contrast, the Pathway-to-Work Project (Juvonen-Posti, Kallanranta, Eksyma, Piirainen, \& Keinänen-Kiukaanniemi, 2002) found participants' distress level to decrease remarkably during rehabilitation, and their perceived competence increased, but their sense of coherence did not change.

Rehabilitation services adopting a salutogenic approach and seeking to enhance a client's sense of coherence can be beneficial in terms of the client's rehabilitation and recovery (Lillefjell, 2008; Griffiths, 2009). Individuals who have been on sick leave and in the process of returning to work might profit from a systematic salutogenic orientation, where the daily actions of the counsellors focus on the resources available (Falkdal et al., 2006). According to Hansen, Edlund, and Henningsson (2006), a reliable prediction of a return to work was influenced by a combination of many factors: the individual's expectations, the number of days of sick leave taken in the past, somatic disorders, level of life satisfaction, and level of the sense of coherence.

In most European countries, there has been a shift within the health and social service sector from highly institutionalized towards more community-focused rehabilitation, such as the use of care farming, which was mentioned earlier (De Krom \& Dessein, 2013). Care farms offer empowerment-oriented and strength-based practices within the community (Hassink et al., 2010). Different care farming interventions aim at starting a rehabilitation process by getting people to participate in an activity, and in this way contribute to improved coping, empowerment, meaningfulness, and quality of life, and if possible a return to work. Care farming interventions might therefore be regarded as pre-vocational rehabilitation where the focus is shifted from disease and disability toward participation and coping (Pedersen, Ihlebæk, \& Kirkevold, 2012.)

\section{Discussion}

Vocational rehabilitation is a process of increasing awareness, enabling people to manage tension, to reflect about, identify, and mobilize internal as well as external resources, and to promote effective coping by finding solutions. Implementation of the salutogenic concept in vocational rehabilitation seems to be of value. The relevance of a salutogenic orientation in vocational rehabilitation is shown in several studies (Falkdal et al., 2006; Griffiths, 2009; Hansen et al., 2006); a strong sense of coherence predicts RTW and a weak sense of coherence predicts no RTW. 
A salutogenic orientation might therefore have several implications when it comes to designing rehabilitation interventions. Enhancement of an individual's sense of coherence seem to be beneficial in terms of the individual's rehabilitation process and recovery (Merz, Bricout, \& Koch, 2001). The main foundation of the concept of sense of coherence is to create coherence between structures and systems (Antonovsky, 1979; Eriksson, 2007), which is considered as a main challenge in the process of RTW. A salutogenic orientation may enhance professionals' ability to appreciate clients' coping strategies and resources. The professionals' competence seems to be essential. A salutogenic orientation includes practical skills, sensitivity, and intuition, and the ability to see the whole situation, contextualize it, and act accordingly, in order to facilitate return to work. RTW counsellors need training to help them focus on assessing and strengthening clients' sense of coherence, by focusing on past experiences that contribute to the sense of coherence. Rehabilitation services should have the goal to strengthen clients' sense of coherence (Lustig et al., 2000; Merz et al., 2001). On a note of caution, using a sense of coherence questionnaire as a screening instrument in RTW practice carries a risk of stigmatization. It is also relevant to question what the individual sense of coherence level at any given time really means for rehabilitation. A sense of coherence assessment might nevertheless be useful in the dialogue between the client and the professional, in order to identify resources (Eriksson, 2007).

\section{Implications for Salutogenesis Research}

Further investigation is required into the development of rehabilitation programs with salutogenic orientation as a part of their foundation. Additionally, more knowledge on how the salutogenic framework can facilitate the return to work process is needed. A salutogenic orientation in outpatient early rehabilitation, where the rehabilitation program and the development of working circumstances progress side-by-side seem to give promising results, and should be further investigated in longitudinal studies. To improve return to work rates, this might indicate a need for a greater part of the rehabilitation process to take place at the workplace/context to which the person is supposed to return after the rehabilitation period. More insight is needed into how disability interacts with comprehensibility, meaningfulness, and manageability (Antonovsky, 1979, 1987), and how this may be applied in rehabilitation counselling settings.

\section{Challenges for the Future}

To assist individuals to achieve their vocational goals, the rehabilitation models place emphasis on assessing and changing the environment as well as changing the individual. A multidimensional approach taking into account a person's physical condition and workplace-related challenges, as well as psychosocial factors, might be of great importance for the person as well as for the society. The key factor is to identify as well as to be able to use and re-use the general resistance resources available, for the intended purpose. Thus, in order to improve vocational rehabilitation in general, a salutogenic approach in all societal levels in policies is required. Coherence is a key, illustrating the main challenges in the rehabilitation research and practice, to create coherence between structures and systems.

Open Access This chapter is distributed under the terms of the Creative Commons Attribution-Noncommercial 2.5 License (http:// creativecommons.org/licenses/by-nc/2.5/) which permits any noncommercial use, distribution, and reproduction in any medium, provided the original author(s) and source are credited.

The images or other third party material in this chapter are included in the work's Creative Commons license, unless indicated otherwise in the credit line; if such material is not included in the work's Creative Commons license and the respective action is not permitted by statutory regulation, users will need to obtain permission from the license holder to duplicate, adapt or reproduce the material.

\section{References}

Ahlgren, Å., Bergroth, A., Ekholm, J., \& Schüldt, K. (2007). Work resumption after vocational rehabilitation: A follow-up two years after completed rehabilitation. Work, 28, 343-354.

Anke, A. G. W., \& Fugl-Meyer, A. R. (2004). Life satisfaction several years after severe multiple trauma-a retrospective investigation. International Journal of Rehabilitation Research, 27(3), 215-227.

Antonovsky, A. (1979). Health, stress and coping. New perspectives on mental and physical well-being. San Francisco: Jossey-Bass.

Antonovsky, A. (1987). Unraveling the mystery of health-how people manage stress and stay well. San Francisco: Jossey-Bass.

Antonovsky, A. (1991). Health-promoting factors at work: The sense of coherence. In R. Kalimo, M. El-Batawi, \& C. Cooper (Eds.), Psychosocial factors at work and their effects on health (pp. 153-167). Geneva: World Health Organization.

Axelsson, L., Andersson, I., Håkansson, A., \& Ejlertsson, G. (2005). Work ethics and general work attitudes in adolescents are related to quality of life, sense of coherence and subjective health—a Swedish questionnaire study. BMC Public Health, 5, 103.

Batt-Rawden, K. B., \& Tellnes, G. (2009). Nature-culture-health activities as a method of rehabilitation: An evaluation of participants' health, quality of life and function. International Journal of Rehabilitation Research, 28(2), 175-180.

Bildt, C., Backstig, L., \& Andersson Hjelm, I.-L. (2006). Work and health in Gnosjo: A longitudinal study. Work, 27(1), 29-43. 
De Krom, M., \& Dessein, J. (2013). Multifunctionality and care farming: Contested discourses and practices in Flanders. Wageningen Journal of Life Sciences, 64-65, 17-24.

Engström, L.-G., \& Janson, S. (2009). Predictors of work presence: Sickness absence in a salutogenic perspective organisation. Work, 33(3), 287-295.

Eriksson, M. (2007). Unravelling the mystery of salutogenesis. The evidence base of the salutogenic research as measured by Antonovsky's Sense of Coherence Scale. Research Report. Åbo Akademis Tryckeri: Turku.

Falkdal, A. H., Edlund, C., \& Dahlgren, L. (2006). Experiences within the process of sick leave. Scandinavian Journal of Occupational Therapy, 13(3), 170-182.

Franche, R. L., Cullen, K., Clarke, J., Irvin, E., Sinclair, S., \& Frank, J. (2005). Workplace-based return-to-work interventions: A systematic review of the quantitative literature. Journal of Occupational Rehabilitation, 15(4), 607-631.

Griffiths, C. A. (2009). Sense of coherence and mental health rehabilitation. Clinical Rehabilitation, 23, 72-78.

Guzman, J., Esmail, R., Karjalainen, K., Malmivaara, A., Irvin, E., \& Bombardier, C. (2002). Multidisciplinary bio-psycho-social rehabilitation for chronic low-back pain. The Cochrane Database of Systematic Reviews, 1, CD000963.

Hansen, A., Edlund, C., \& Bränholm, I. B. (2005). Significant resources needed for return to work after sick leave. Work, 25(3), 231-240.

Hansen, A., Edlund, G., \& Henningsson, M. (2006). Factors relevant to a return to work: A multivariate approach. Work, 26(2), 179-190.

Hassink, J., Elings, M., Zweekhorst, M., van den Nieuwenhuizen, N., \& Smit, A. (2010). Care farms in the Netherlands: Attractive empowerment-oriented and strengths-based practices in the community. Health \& Place, 16(3), 423-430.

Hoefsmit, N., Houkes, I., \& Nijhuis, F. J. N. (2012). Intervention characteristics that facilitate return to work after sickness absence: A systematic literature review. Journal of Occupational Rehabilitation, 22(4), 462-477.

Hoffman, B. M., Papas, R. K., Chatkoff, D. K., \& Kerns, R. D. (2007). Meta-analysis of psychological interventions for chronic low back pain. Health Psychology, 26(1), 1-9.

Höge, T., \& Büssing, A. (2004). The impact of sense of coherence and negative affectivity on the work stressor-strain relationship. Journal of Occupational Health Psychology, 9, 195-205.

Ilmarinen, J. (2006). The ageing workforce-challenges for occupational health. Occupational Medicine, 56(6), 362-364.

Jakobsen, K. (2004). If work doesn't work: How to enable occupational justice? Journal of Occupational Science, 11, 125-134.

Jensen Claudi, A. G. (2013). Towards a parsimonious program theory of return to work Intervention. Work, 44(2), 155-164.

Juvonen-Posti, P., Kallanranta, T., Eksyma, S. L., Piirainen, K., \& Keinänen-Kiukaanniemi, S. (2002). Into work, through tailored paths: A two-year follow-up of the return-to-work rehabilitation and re-employment project. International Journal of Rehabilitation Research, 25(4), 313-330.

Kaiser, P. O., Mattsson, B., Marklund, S., \& Wimo, A. (2001). The impact of psychosocial 'markers' on the outcome of rehabilitation. Disability and Rehabilitation, 23(10), 430-435.

Kaiser, P. O., Mattsson, B., Marklund, S., \& Wimo, A. (2006). Sense of coherence and vocational rehabilitation of persons with chronic musculoskeletal disorders-gender aspects. The Journal of Men's Health \& Gender, 3(4), 373-378.

Kivimäki, M., Kalimo, R., \& Toppinen, S. (1998). Sense of coherence as a modifier of occupational stress exposure, stress perception, and experienced strain: A study of industrial managers. Psychological Reports, 83, 971-981.

Lamminpää, A., Kuoppala, J., Väänänen-Tomppo, I., \& Hinkka, K. (2012). Employee and work-related predictors for entering rehabilitation: A cohort study of civil servants. Journal of Rehabilitation Medicine, 44(8), 669-676.

Lillefjell, M. (2006). Gender differences in psychosocial influence and rehabilitation outcomes for work-disabled individuals with chronic musculoskeletal pain. Journal of Occupational Rehabilitation, 16 (4), 659-674.

Lillefjell, M. (2008). Function and work ability following multidisciplinary rehabilitation for individuals with chronic musculoskeletal pain. Thesis for the degree philosophiae doctor Trondheim, Norwegian University of Science and Technology.

Lillefjell, M., \& Jakobsen, K. (2007). Sense of coherence as a predictor of work re-entry following multidisciplinary rehabilitation for individuals with chronic musculoskeletal pain. Journal of Occupational Health Psychology, 12(3), 222-231.

Lundberg, O., \& Nyström Peck, M. (1994). Sense of coherence, social structure and health. European Journal of Public Health, 4(4), 252-257.

Lustig, D. C., Rosenthal, D. A., Strauser, D. R., \& Haynes, K. (2000). The relationship between sense of coherence and adjustment in persons with disabilities. Rehabilitation Counseling Bulletin, 43 (3), 134-141.

Lydell, M., Marklund, B., Baigi, A., Mattsson, B., \& Måånsson, J. (2011). Return or no return-psychosocial factors related to sick leave in persons with musculoskeletal disorders: a prospective cohort study. Disability and Rehabilitation, 33(8), 661-666.

Martin, M. H. T., Nielsen, M. B. D., Madsen, I. E. H., Petersen, S. M. A., Lange, T., \& Rugulies, R. (2013). Effectiveness of a coordinated and tailored return-to-work intervention for sickness absence beneficiaries with mental health problems. Journal of Occupational Rehabilitation, 23(4), 621-630.

Merz, M. A., Bricout, J. C., \& Koch, L. C. (2001). Disability and job stress: Implications for vocational rehabilitation planning. Work, 17 (2), 85-95

Newton, S. E. (1999). Relationship of hardiness and sense of coherence to post-liver transplant return to work. Holistic Nursing Practice, 13 (3), 71-79.

Pedersen, I., Ihlebæk, C., \& Kirkevold, M. (2012). An interview study on important elements in farm animal-assisted interventions for persons with clinical depression. Disability and Rehabilitation, 34 (18), 1526-1534.

Ramel, E., Rosberg, H.-E., Dahlin, L. B., \& Cederlund, R. I. (2003). Return to work after a serious hand injury. Work, 44(4), 459-469.

Shaw, L., Segal, R., Poljatako, H., \& Harburn, K. (2002). Understanding return to work behaviours: Promoting the importance of individual perceptions in the study of return to work. Disability and Rehabilitation, 24, 185-195.

Staal, J. B., Rainville, J., Fritz, J., van Mechelen, W., \& Pransky, G. (2005). Physical exercise intervention to improve disability and return to work in low back pain; current insights and opportunities for improvement. Journal of Occupational Rehabilitation, 15, 491-505.

Suominen, S., Gould, R., Ahvenainen, J., Vahtera, J., Uutela, A., \& Koskenvuo, M. (2005). Sense of coherence and disability pensions. A nationwide, register based prospective population study of 2196 adult Finns. Journal of Epidemiology and Community Health, 59, $455-459$.

Väänänen-Tomppo, I., Janatuinen, E., \& Törnqvist, R. (2005). All well at work? Evaluation of workplace-based early rehabilitation in the Finnish State administration. International Journal of Rehabilitation Research, 25(4), 313-330.

Vastamaki, J., Moser, K., \& Paul, K. I. (2009). How stable is sense of coherence? Changes following an intervention for unemployed individuals. Scandinavian Journal of Psychology, 50, 161-171.

Virtanen, P., \& Koivisto, A.-M. (2001). Wellbeing of professionals at entry into the labour market: A follow up survey of medicine and 
architecture students. Journal of Epidemiology and Community Health, 55, 831-835.

Volanen, S. M., Lahelma, E., Silventoinen, K., \& Suominen, S. (2004). Factors contributing to sense of coherence among men and women. European Journal of Public Health, 14(3), 322-330.
Volanen, S.-M., Suominen, S., Lahelma, E., Koskenvuo, K., Koskenvuo, M., \& Silventoinen, K. (2010). Sense of coherence and intentions to retire early among Finnish women and men. BMC Public Health, 10, 22.

World Health Organization. (2011). World Report on Disability. ISBN 9789240686366 (ePub). WHO Press; Geneva, Switzerland 